\author{
Professor Leonardo BADEA \\ West University of Timisoara \\ E-mail: leobadea@yahoo.com \\ Valentin IONESCU \\ Director of the Strategy and Financial Stability \\ Financial Supervisory Authority \\ E-mail:valentine.ionescu@ asfromania.ro \\ Adina-Alexandra GUZUN, PhD \\ West University of Timisoara \\ E-mail: alexandraguzun@yahoo.com
}

\title{
WHAT IS THE CAUSAL RELATIONSHIP BETWEEN STOXX EUROPE 600 SECTORS? BUT BETWEEN LARGE FIRMS AND SMALL FIRMS?
}

\begin{abstract}
This paper aims to establish whether there is a relationship between the main industries of the STOXX EURO 600 index. Another research question is addressed in this article: what is the link between small and large firms? In order to answer these two questions, we will use various econometric models such as VAR-impulse response functions, Granger causality tests and GARCH models for modeling the volatility. The empirical results pointed out a positive relationship between all the sectors selected and STOXX 600 index. The Granger causality test showed a unidirectional causal relationship from the insurance sector to STOXX 600 and a bidirectional causal relationship between automobiles \& parts, construction and material components, retail, telecommunications, utilities and STOXX600. We strongly believe that through our results we will help investors in their decision-making process, academic research and the policy makers and will improve supervisory process.

Keywords: capital market, financial stability, volatility clustering, GARCH, VAR, impulse-response functions, Granger causality.
\end{abstract}

\section{JEL Classification: C22, C32, G1}

\section{Introduction}

Small firms and large firms can operate in the same market, under the same legal arrangement but they have a different organizational approach in terms of operations, legal structure, financial arrangements, shareholders etc. It is precisely these differences that make an area of dynamic influence between the two types of companies by size. Practice and statistics shows us that the influence is generally from large companies to small firms, but not as a general rules. 
Leonardo Badea, ValentinIonescu, Adina Alexandra Guzun

Despite of the fact that at the first glance larger firms can ,survive, without small ones this is like a stock-market without scalpers (according to investopia, a scalper is a person who holds a position in a security for a short period of time in an attempt to make a profit. Scalpers buy and sell many times in a day with the objective of taking small consistent profits out of the market).

On the other hand, a market without large firms is similar with a stock market without market makers. In an efficient stock market, we need both to be in, in order to have covered the need for large quantities and the need for smaller spreads between buy and sell. Similar in a business environment we need small companies, sometimes niche ones, to the same extent as large firms.

Thus, understanding the dynamic interrelationships between the returns on size-based portfolios is useful not only in theoretical and empirical academic work, but also to regulators, investors, speculators, and hedgers.

The present paper has the following form: a presentation of the literature review and of the database and the methodology that we have used in our research.

The next part presents the results of the previous research and a short discussion on their impact and the last section presents the conclusions of our study.

\section{Literature Review}

Pardo and Torro (2003) focused on analysing the dynamic relationships between large and small companies using IBEX-35 index and IBEXComplementario for 1990-2002 period, which are the most important indexes of the Spanish Stock Exchange. With the help of multivariate GARCH models and impulse-response functions they conclude that bad news about small firms can cause volatility for both types of companies (large or small).

Hodgson, Masih and Masih (1999) explored the relationship between large, medium and small stocks in Australia by applying Johansen cointegration test, VECM (vector error-correction model) and variance decomposition. The empirical evidence showed that during a bear market phase the price of large firms provided the dominant price lead, while in a bull market phase, the small firms became more powerful, in the short and long term and their stock prices are relatively more exogenous.

Francis, B.B., Hunter, D.M., Mougoué, M. (2003) examined the causal relationship between large and small firms by approaching linear and nonlinear causality tests using daily returns stocks data. They revealed that small companies are leaded by the large ones but they also found significant nonlinear causality, which is bidirectional.

During the expansion and recession, phases of the business cycle that expected returns and risk for both small and large firms are different according to 
What is the Causal Relationship between STOXX EUROPE 600 Sectors? But between Large Firms and Small Firms?

Perez-Quiros and Timmerman (2000). The small firms present a greater degree of asymmetry in their expected returns across during these two phases.

Munteanu, Filip and Pece (2014) investigated if between 2005 and 2013 there is any link on the evolution of returns gained in 12 Emerging European Countries (EEC) and U.S., by using a VECM and a Granger causality test. They have found that there is a strongly connection between U.S and the EEC financial markets.

Keim (1983) studied the example of two representative US stock exchanges and found out that the daily abnormal return of the NYSE and AMEX stock distributions in January is larger compared to the rest of eleven months and that the relationship between abnormal yield and size is always negative accentuated in January.

Lo and MacKinlay (1990) pointed out that the returns of smaller stocks firms are correlated with past returns of larger stocks firm, but not vice-versa.

Conrad, Gultekin, and Kaul (1991) showed using GARCH models that volatility of the large firms are important to the future dynamics of their own returns as well as the returns of smaller firms and the shocks of the smaller firms have no impact on the returns of larger companies.

Ho, Ernst and Zhang (2011) focused on studying the dynamics of small cap and large firm prices and they found out a consistently negative and highly significant relationship between small and large firms stock prices.

\section{Quantitative framework \\ 3.1 Variables and data}

The quantitative part of our study is focused on daily data (January 2001March 2019) and data sources is Datastream. The selected variables, alongside their definitions, period, and source, are exhibited in Table 1.

We have selected a number of optimized STOXX indices representing various sectors of the economy (Banks, Health, Industrial Products and Services, Insurance, Personal and Household Products, Food \& Beverage, Petroleum and Gas, Chemicals, Telecom, Utilities, Retail, Auto and Parts, Mass Media, Basic Resources, Construction and Material, Real Estate, Travel and Leisure, Financial Services). Regarding the study about the relationships between small and large firms, we have selected two stock indices STOXX EUROPE SMALL 200 and STOXX EUROPE LARGE 200.

The STOXX 600 is obtained from the STOXX Europe Total Market Index (TMI) and is a subdivision of the STOXX Global 1800 Index. STOXX Europe 600 index has a total number of 600 units and represents large, medium and small companies in 17 European countries: Austria, Finland, Belgium, Sweden, Denmark, 
France, Italy, Germany, Ireland, Luxembourg, Norway, Poland, Spain, Switzerland, Portugal and the United Kingdom.

\subsection{Econometric models}

In determining our main objective, we will use the VAR models, impulseresponse functions, Granger causality test and GARCH models.

We can use the below formula in order to calculate the daily returns:

$$
R_{i, t}=\ln \left(\frac{P_{i, t}}{P_{i, t-1}}\right)
$$

where $R_{i, t}$ is the yield of the asset $\mathrm{i}$ in period $\mathrm{t}, P_{i, t}$ is the asset price $\mathrm{i}$ in period $\mathrm{t}$ and $P_{i, t-1}$ is the price of the asset in the $\mathrm{t}-1$ period. As per the scientific literature, the logarithmic yields are preferred, which had to show a normal distribution.

Testing the unit roots of the series is the first step that we have to do. In order to achieve what we have proposed, we have chosen the Augmented DickeyFuller (ADF) unit root test in order to check the non-stationary presumption. The equation of the $\mathrm{ADF}$ test is showed below:

$$
\Delta y_{t}=\alpha+\beta t+\rho y_{t}+\sum_{j=1}^{k} y_{t-1} \Delta y_{t-j}+\varepsilon_{t}, \mathrm{t}=1, \ldots, \mathrm{T}
$$

Where $t$ is a time trend, $\mathrm{T}=$ length sample, $\mathrm{k}$ is a coefficient that has the length of the gap between the dependent variables.

The null assumption presumes that the variable has a unit root, and the alternative is that a stationary process generated the variable.

The study of financial time series uses the GARCH models such as evolution of stock market prices, the exchange rate or rate of return on financial assets, and so forth.These models are important because of the differences betweenunconditional and conditionaloptions. Unconditional variants are expected to be time-independent and conditional variants are expected to be linked to past experiences that are involved in the multitude of data at time $\mathrm{t}-1$.

Engle (1982) introduced the ARCH models and Generalized (GARCH) by Bollerslev(1986). A GARCH model permits to the conditional variation to depend on its previous lags. Through GARCH models, the AR process transforms the ARCH model into an ARMA process by adding a MA process. The GARCH model $(\mathrm{p}, \mathrm{q})$ is:

$$
\begin{aligned}
& y_{t}=\mu+\varepsilon_{t} \sim N\left(0, \sigma^{2}\right) \\
& \sigma^{2}=\omega+\alpha_{1} \varepsilon_{t-1}^{2}+\ldots+\alpha_{q} \varepsilon_{t-q}^{2}+\beta_{1} \sigma_{t-1}^{2}+\ldots+\beta_{p} \sigma_{t-p}^{2},
\end{aligned}
$$

where $\omega>0$ and $\alpha_{\mathrm{i}} \geq 0, \beta_{\mathrm{i}} \geq 0$.

As we can see, the conditioned variance depends on the historical values of the shocks as well as on the values of the variance which took place in the past. The coefficients $\sigma_{t-p}^{2}$ represent persistence of volatility, and the coefficients $\varepsilon_{t-p}^{2}$ 
What is the Causal Relationship between STOXX EUROPE 600 Sectors? But between Large Firms and Small Firms?

represent the reaction of volatility to shocks in the financial market. The parameter $\mathrm{p}$ is the order of the GARCH terms and $\mathrm{q}$ is the order of the ARCH terms.

GARCH $(1,1)$ represent the most appropriate model by majority ofresearchers to adapt the volatility evolution.

The model that permits stocks to have nonsymmetrical effects on conditional variants is the EGARCH model (exponential GARCH)(which was brought in 1991 by Nelson). The result of information is considered exponential, not square as before. The EGARCH model $(1,1)$, the equation is:

$$
\log \left(\sigma_{t}^{2}\right)=\omega+\beta \log \left(\sigma_{t-1}^{2}\right)+\alpha \frac{\left|\varepsilon_{t-1}\right|}{\sigma_{t-1}}+\gamma \frac{\varepsilon_{t-1}}{\sigma_{t-1}}
$$

As you can see $\gamma$ is the measure of the leverage effect. If $\gamma>0$ there is leverage and the impact is asymmetrical if $\gamma \neq 0$.

In order to make causality analyses of the two variables, as per the literature, we can consider the Granger causality test. According to it, $\mathrm{x}$ does not Granger-cause $y$ in the first regression and $y$ does not Granger-cause $x$ in the second regression. We have bivariate regressions:

$$
\begin{aligned}
& \mathrm{y}_{\mathrm{t}}=\alpha_{0}+\alpha_{1} \mathrm{y}_{\mathrm{t}-1}+\cdots+\alpha_{\mathrm{p}} \mathrm{y}_{\mathrm{t}-\mathrm{p}}+\beta_{1} \mathrm{x}_{\mathrm{t}-1}+\cdots+\beta_{\mathrm{p}} \mathrm{x}_{-\mathrm{p}}+\epsilon_{\mathrm{t}} \\
& \mathrm{x}_{\mathrm{t}}=\alpha_{0}+\alpha_{1} \mathrm{x}_{\mathrm{t}-1}+\cdots+\alpha_{\mathrm{p}} \mathrm{x}_{\mathrm{t}-\mathrm{p}}+\beta_{1} \mathrm{y}_{\mathrm{t}-1}+\cdots+\beta_{\mathrm{p}} \mathrm{y}_{-\mathrm{p}}+\mathrm{u}_{\mathrm{t}}
\end{aligned}
$$

\section{Empirical findings and discussions}

4.1. Causality investigations

Tables 1 presents descriptive statistics of daily logarithmic returns of the STOXX 600 indices. The return series is negatively inclined (with the exception of indices for Automobiles \& Parts and banks).

Table 1. Descriptive statistics of variables

\begin{tabular}{|l|c|c|c|c|c|c|}
\hline & Mean & St. Dev. & Skewness & Kurtosis & $\begin{array}{c}\text { Jarque- } \\
\text { Bera }\end{array}$ & Prob \\
\hline AUTO PARTS & 0.000181 & 0.020059 & $\mathbf{2 . 1 6 4 9 6 2}$ & 94.49211 & 1664977 & 0 \\
\hline BANKS & -0.00021 & 0.017164 & $\mathbf{0 . 0 1 0 4 2 9}$ & 11.7182 & 15084.31 & 0 \\
\hline BASIC_RESOURCE & 0.000166 & 0.020837 & -0.15756 & 10.08873 & 9992.245 & 0 \\
\hline CHEMICALS & 0.000219 & 0.013246 & -0.06909 & 8.783164 & 6641.225 & 0 \\
\hline CON_MAT & 0.000162 & 0.014315 & -0.08026 & 8.900027 & 6913.512 & 0 \\
\hline FINANCIAL_SVS & $7.48 E-05$ & 0.014417 & -0.32327 & 10.36365 & 10844.02 & 0 \\
\hline
\end{tabular}


Leonardo Badea, ValentinIonescu, Adina Alexandra Guzun

\begin{tabular}{|l|c|c|c|c|c|c|}
\hline FOOD_BEV & 0.000227 & 0.009632 & -0.28032 & 7.694985 & 4436.975 & 0 \\
\hline HEALTH_CARE & 0.000101 & 0.010563 & -0.03927 & 8.537707 & 6087.187 & 0 \\
\hline INDS_GDS_SVS & $9.47 \mathrm{E}-05$ & 0.013271 & -0.2238 & 8.527673 & 6103.687 & 0 \\
\hline INSURANCE & $-9.03 \mathrm{E}-05$ & 0.017247 & -0.01698 & 10.94042 & 12513.08 & 0 \\
\hline MEDIA & $-8.22 \mathrm{E}-05$ & 0.013218 & -0.06066 & 7.865028 & 4700.133 & 0 \\
\hline OIL_GAS & $-1.90 \mathrm{E}-06$ & 0.01472 & -0.1717 & 9.111622 & 7436.202 & 0 \\
\hline PERS_H_H_GDS & 0.00024 & 0.011577 & -0.18071 & 7.525597 & 4090.556 & 0 \\
\hline REAL_ESTATE & 0.000123 & 0.012362 & -0.39742 & 8.98896 & 7243.609 & 0 \\
\hline RETAIL & $2.18 \mathrm{E}-05$ & 0.011548 & -0.24459 & 7.62314 & 4289.223 & 0 \\
\hline TELECOM & -0.00014 & 0.013781 & 0.070669 & 7.74493 & 4472.126 & 0 \\
\hline TRAVEL_LEIS & $6.48 \mathrm{E}-05$ & 0.013242 & -0.42904 & 8.77585 & 6766.785 & 0 \\
\hline UTILITIES & $1.04 \mathrm{E}-05$ & 0.011674 & -0.0204 & 14.85279 & 27881.47 & 0 \\
\hline EURO_STOXX & $-7.94 \mathrm{E}-06$ & 0.013117 & -0.115 & 8.127129 & 5227.463 & 0 \\
\hline STOXX_EUROPE_600 & $1.63 \mathrm{E}-05$ & 0.011973 & -0.1749 & 8.957236 & 7067.302 & 0 \\
\hline STOXX_GLOBAL_1800 & $8.39 \mathrm{E}-05$ & 0.009984 & -0.18545 & 8.33108 & 5667.569 & 0 \\
\hline $\begin{array}{l}\text { STOXX EUROPE } \\
\text { SMALL_200 }\end{array}$ & 0.000108 & 0.009894 & -0.74356 & 10.55296 & 20772.64 & 0 \\
\hline $\begin{array}{l}\text { STOXX EUROPE } \\
\text { LARGE 200 }\end{array}$ & 0.000193 & 0.011269 & -0.32799 & 10.05214 & 17584.21 & 0 \\
\hline
\end{tabular}

Source: Authors' work.

According to the ADF stationarity test, all data series are stationary, being integrated with order I (0). It can also be seen from previous charts. The results can be found in the appendix to the article.

The results point out that the coefficients are statistically significant and it can be seen a direct relationship between STOXX GLOBAL 1800/ EURO STOXX PRICE INDEX and STOXX 600, with a stronger influence coming from EURO STOXX PRICE INDEX (the index includes companies operating in the euro area).

\section{Table 2. Equation of the STOXX 600 index component}

\begin{tabular}{|l|c|c|c|r|}
\hline $\begin{array}{l}\text { Dependent Variable: } \\
\text { STOXX_EUROPE_600 }\end{array}$ & & & & \\
\hline Method: Least Squares & & & & \\
\hline Sample: $1 / 01 / 20014 / 03 / 2019$ & & & & \\
\hline Included observations: 4763 & & & & \\
\hline Variable & Coefficient & Std. Error & t-Statistic & Prob. \\
\hline STOXX_GLOBAL_1800 & 0.131496 & 0.005213 & 25.22595 & 0 \\
\hline EURO_STOXX_PRICE_INDEX & 0.817385 & 0.003968 & 206.0151 & 0 \\
\hline
\end{tabular}


What is the Causal Relationship between STOXX EUROPE 600 Sectors? But between Large Firms and Small Firms?

\begin{tabular}{|c|c|c|c|c|}
\hline $\mathrm{C}$ & $1.18 \mathrm{E}-05$ & $3.50 \mathrm{E}-05$ & 0.337131 & 0.736 \\
\hline R-squared & 0.959269 & $\begin{array}{l}\text { Mean dependent } \\
\text { var }\end{array}$ & & $1.63 \mathrm{E}-05$ \\
\hline Adjusted R-squared & 0.959252 & $\begin{array}{l}\text { S.D. dependent } \\
\text { var }\end{array}$ & & $\begin{array}{r}0.01197 \\
3\end{array}$ \\
\hline S.E. of regression & 0.002417 & $\begin{array}{l}\text { Akaike info } \\
\text { criterion }\end{array}$ & & -9.21206 \\
\hline Sum squared resid & 0.027804 & Schwarz criterion & & -9.20799 \\
\hline Log likelihood & 21941.53 & $\begin{array}{l}\text { Hannan-Quinn } \\
\text { criter. }\end{array}$ & & -9.21063 \\
\hline F-statistic & 56052.16 & $\begin{array}{l}\text { Durbin-Watson } \\
\text { stat }\end{array}$ & & 2.20917 \\
\hline Prob(F-statistic) & 0 & & & \\
\hline
\end{tabular}

For a deeper research is necessary to look at the sectorial influence by selecting the main industry components of the STOXX 600 index such as Banks, Health, Industrial Products and Services, Insurance, Personal and Household Products, Food \& Beverage, Petroleum and Gas, Chemicals, Telecom, Utilities, Retail, Auto and Parts, Mass Media, Basic Resources, Construction and Material, Real Estate, Travel and Leisure, Financial Services.

According to the empirical results, Banks have the largest influence from the industry selected. Other significant influence is done by Health Care industry and INDS_GDS_SVS. All the sectors have a positive impact on STOXX 600 index with only one exception, namely Real Estate, his coefficient being not statistically significant.

Table 3. Equation of the STOXX 600 index by sectors

\begin{tabular}{|l|c|c|c|c|}
\hline \multicolumn{2}{|l|}{ Dependent Variable: STOXX_EUROPE_600 } & \\
\hline Method: Least Squares & & & & \\
\hline $\begin{array}{l}\text { Sample: } 1 / 01 / 2001 \\
\text { 4/03/2019 }\end{array}$ & & & & \\
\hline Included observations: 4763 & & & & \\
\hline Variable & Coefficient & Std. Error & t-Statistic & Prob. \\
\hline AUTO_PARTS & 0.029223 & 0.000776 & 37.6446 & 0 \\
\hline BANKS & 0.122245 & 0.001727 & 70.77968 & 0 \\
\hline BASIC_RESOURCE & 0.029638 & 0.00102 & 29.05213 & 0 \\
\hline CHEMICALS & 0.037106 & 0.001849 & 20.06283 & 0 \\
\hline CON_MAT & 0.015412 & 0.002089 & 7.377878 & 0 \\
\hline FINANCIAL_SVS & 0.044072 & 0.002382 & 18.50493 & 0 \\
\hline FOOD_BEV & 0.055317 & 0.002146 & 25.7731 & 0 \\
\hline HEALTH_CARE & 0.110633 & 0.001777 & 62.25558 & 0 \\
\hline
\end{tabular}


Leonardo Badea, ValentinIonescu, Adina Alexandra Guzun

\begin{tabular}{|l|c|c|c|c|}
\hline MEDIA & 0.047022 & 0.001937 & 24.28051 & 0 \\
\hline INSURANCE & 0.065504 & 0.00178 & 36.80767 & 0 \\
\hline INDS_GDS_SVS & 0.107754 & 0.002886 & 37.33991 & 0 \\
\hline OIL_GAS & 0.09131 & 0.001405 & 64.97834 & 0 \\
\hline PERS_H_H_GDS & 0.0956 & 0.002466 & 38.76492 & 0 \\
\hline REAL_ESTATE & -0.001593 & 0.001578 & -1.00962 & 0.3127 \\
\hline RETAIL & 0.018214 & 0.002062 & 8.832333 & 0 \\
\hline TELECOM & 0.093606 & 0.001487 & 62.92958 & 0 \\
\hline TRAVEL_LEIS & 0.009931 & 0.001828 & 5.434319 & 0 \\
\hline UTILITIES & 0.039111 & 0.001818 & 21.50918 & 0 \\
\hline C & $-1.66 E-05$ & $1.16 E-05$ & -1.43395 & 0.1517 \\
\hline R-squared & 0.995571 & Mean dependent var & & $1.63 \mathrm{E}-05$ \\
\hline Adjusted R-squared & 0.995554 & S.D. dependent var & & 0.011973 \\
\hline S.E. of regression & 0.000798 & $\begin{array}{c}\text { Akaike info } \\
\text { criterion }\end{array}$ & -11.4241 \\
\hline Sum squared resid & 0.003024 & Schwarz criterion & & -11.3983 \\
\hline Log likelihood & 27225.48 & Hannan-Quinn & & -11.415 \\
& & criter. & & 1.98713 \\
\hline F-statistic & 59239.3 & Durbin-Watson stat & & \\
\hline Prob(F-statistic) & 0 & & & \\
\hline
\end{tabular}

Source: Datastream, authors' calculations

We are also interested in the relationship between large and small companies. Based on the estimates made, there is a statistically significant link between them, and the biggest contribution seems to have the big companies on the STOXX 6000.

Table 4. Equation of the STOXX_EUROPE_600 index by small and large firms

\begin{tabular}{|c|c|c|c|c|}
\hline \multicolumn{5}{|c|}{ Dependent Variable: STOXX_EUROPE_600 } \\
\hline Method: Least Squares & & & & \\
\hline \multicolumn{5}{|c|}{ Sample (adjusted): 1/05/1987 4/01/2019 } \\
\hline \multicolumn{5}{|c|}{ Included observations: 8411 after adjustments } \\
\hline Variable & Coefficient & Std. Error & $\begin{array}{c}\mathrm{t}- \\
\text { Statistic }\end{array}$ & Prob. \\
\hline STOXX_EUROPE_LARGE_200 & 0.857043 & 0.000797 & 1075.778 & 0 \\
\hline STOXX_EUROPE_SMALL_200 & 0.142701 & 0.000907 & 157.2673 & 0 \\
\hline $\mathrm{C}$ & $1.56 \mathrm{E}-06$ & $4.29 \mathrm{E}-06$ & 0.362958 & 0.7166 \\
\hline R-squared & 0.998703 & Mean dependent var & & 0.000183 \\
\hline Adjusted R-squared & 0.998703 & S.D. dependent var & & 0.010928 \\
\hline S.E. of regression & 0.000394 & Akaike info criterion & & -12.8422 \\
\hline Sum squared resid & 0.001302 & Schwarz criterion & & -12.8397 \\
\hline
\end{tabular}


What is the Causal Relationship between STOXX EUROPE 600 Sectors? But between Large Firms and Small Firms?

\begin{tabular}{|l|r|l|l|r|}
\hline Log likelihood & 54011.05 & Hannan-Quinn criter. & & -12.8414 \\
\hline F-statistic & 3237382 & Durbin-Watson stat & & 2.091564 \\
\hline Prob(F-statistic) & 0 & & & \\
\hline
\end{tabular}

Source: Authors`work

With the VAR model, we will analyze how the sectors of the STOXX 600 Index are influencing and how they influence the evolution of the STOXX index.

In Figure 4 are presented thevariance decomposition and the impulse response function and allow us to clear out if the behavior of one variable is linked to innovations of another variable in the future. However, the impulse response function shows us how much the STOXX 600 variable reacts to other variables' shocks. The horizontal axis (X) of the chart is the number of periods and the vertical axis (Y) represents the totality of the variable which are expected to be modified because of a unit impulse.

We have outlined the impulse response results below for some of the sectors of activity in the STOXX 600 index.

If we take into consideration the impulse-response functions, we can show how the impact of the sectors, represented by various indices, looks like. As we have presented in the graphs, telecommunications, media, insurance, retail and real estate had a negative impact from the beginning on STOXX600 index. Although some of them present a positive reaction in the first period and then increase, decrease or fluctuate along the way.

We have also studied how large and small companies react as a result of shocks.Also, other interesting conclusions can be drawn from the analysis of small and large firms.The STOXX 600 index reacts positively in the first period as a result of the positive innovation applied to large companies, and negative as a result of the shock applied to small companies.
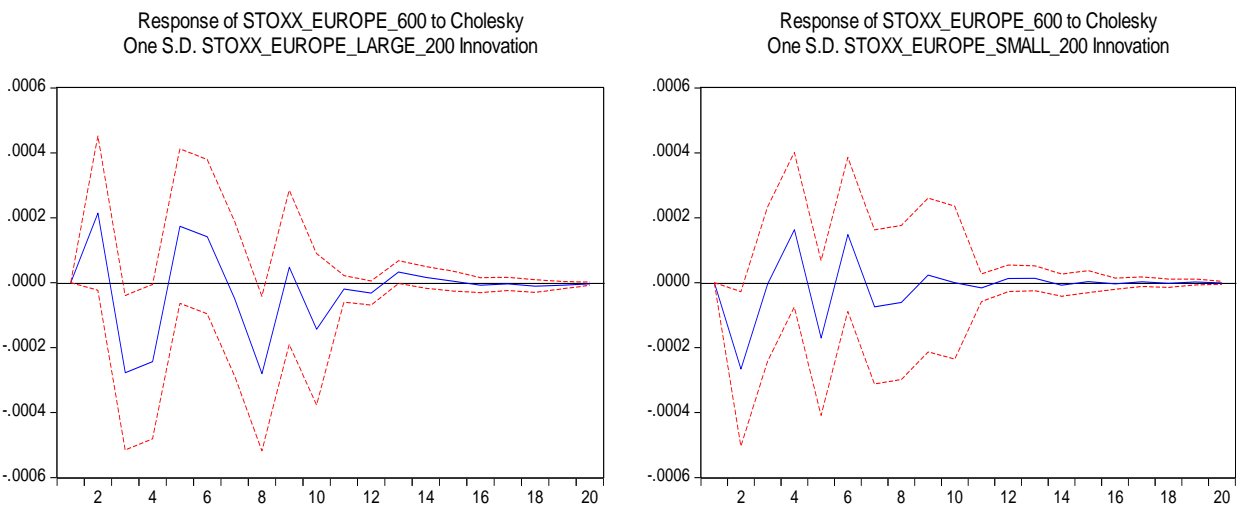

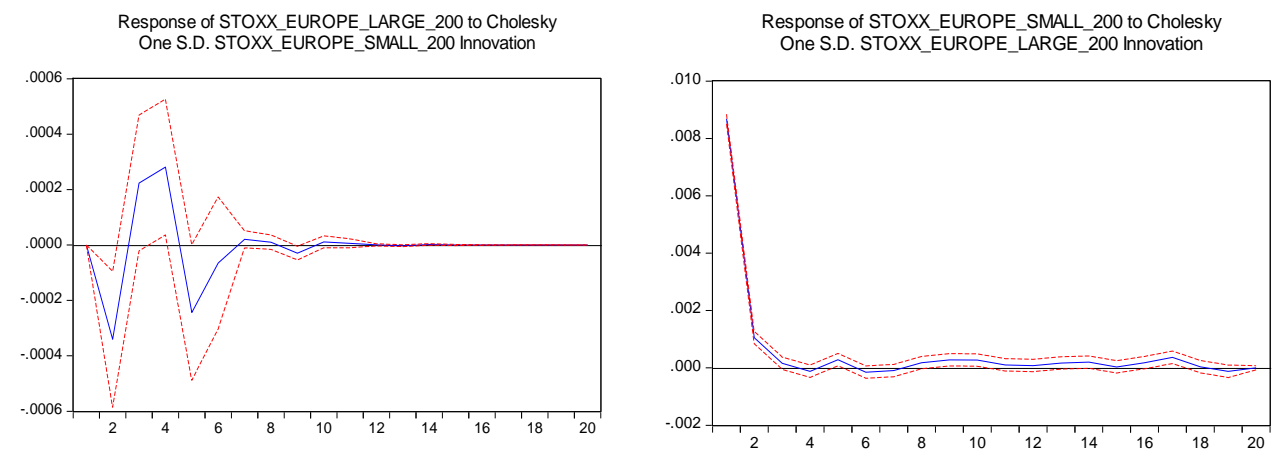

Figure 1. The impulse response function of the STOXX indexes for small and large companies

Source: Authors'work.

In order to analyze causality between two variables, as per the literature review, we can choose the Granger causality test. In this regard,the mean must be 0 and the data series must be stationary. After their conversion, we have obtained the following results; more details can be found in the annex to the paper.

We have achieved the following:

- Unidirectional causal relationship from the insurance sector to STOXX 600;

- Bidirectional causal relationship between auto, construction and material components, retail, telecom, utilities and STOXX600.

We also notice two-way causal relations between:

- Insurance and banks

- Insurance and financial services

- Health and financial services

- Oil and banks

- Insurance and auto

- Banks and cars

- Oil and financial services

Causality also occurs between small and large companies. The Granger causality test allows us to confirm the presence of a bidirectional causality between them. 
What is the Causal Relationship between STOXX EUROPE 600 Sectors? But between Large Firms and Small Firms?

Table 5.The results of the Granger causality test Null Hypothesis:

Prob.

\begin{tabular}{l|l}
$\begin{array}{l}\text { STOXX_EUROPE_SMALL_200 does not Granger } \\
\text { Cause STOXX_EUROPE_LARGE_200 }\end{array}$ & $\mathbf{8 . 0 0 E - 0 5}$ \\
$\begin{array}{l}\text { STOXX_EUROPE_LARGE_200 does not Granger } \\
\text { Cause STOXX_EUROPE_SMALL_200 }\end{array}$ & $\mathbf{7 . 0 0 E - 1 0}$
\end{tabular}

Source: Authors' work.

\subsection{Studying volatility}

Quantiles-Quantiles plot is a simple method which is preferred in order to make a comparison between two distributions and it is the graph of an empirical distribution versus a theoretical distribution (the normal distribution).In our case the division is not normal, but in case the empirical division is normal, the Q-Q graph could be the first bisector.

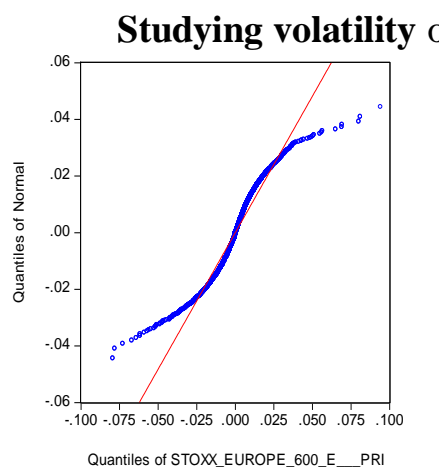

\section{STOXX 600 and component industries}

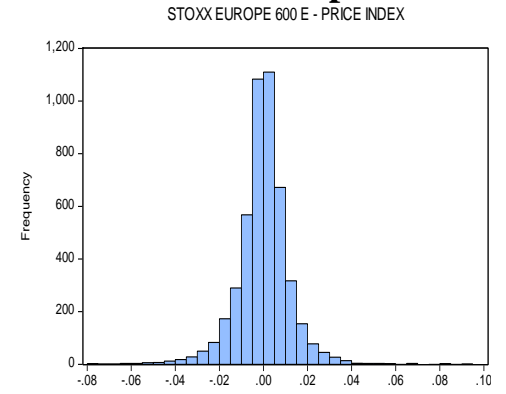

Figure 2. The Q-Q plot and the density graph

Source: Authors' work.

Table 6. Autocorrelation (AC), partial autocorrelation (PAC) and Q test with lag 20 for daily yields

\begin{tabular}{|l|r|r|r|r|r|}
\hline Variable & \multicolumn{1}{|l|}{ Lag } & \multicolumn{1}{|l|}{ AC } & \multicolumn{1}{c|}{ PAC } & \multicolumn{1}{c|}{ Q-Stat } & \multicolumn{1}{c|}{ Prob } \\
\hline STOXX600 & 20 & 0.012 & 0.007 & 70.378 & 0 \\
\hline Banks & 20 & 0.024 & 0.023 & 78.92 & 0 \\
\hline Financial services & 20 & 0.017 & 0.014 & 88.507 & 0 \\
\hline Insurance & 20 & -0.007 & -0.005 & 107.22 & 0 \\
\hline
\end{tabular}


Leonardo Badea, ValentinIonescu, Adina Alexandra Guzun

\begin{tabular}{|l|r|r|r|r|r|} 
Oil/Gas & 20 & 0.002 & -0.004 & 56.569 & 0 \\
\hline Healtcare & 20 & 0.015 & 0.008 & 54.05 & 0 \\
\hline Auto & 20 & 0.001 & -0.012 & 119.75 & 0 \\
\hline Telecom & 20 & 0.013 & 0.006 & 85.855 & 0 \\
\hline Retail & 20 & 0.009 & 0.007 & 33.6 & 0.029 \\
\hline
\end{tabular}

Source: Authors' work.

In table 6 we wanted to show the volatility of the main sectors STOXX 6000 indices. We have used EGARCH $(1,1)$ equation in order to generate the historical volatility series.

As it is shown, volatility had different evolutions over the analyzed period 2001-2019.The highest volatility can be noticed in 2008-2009 period, followed by a decreasing period, in 2010. A new episode of volatility was noticed in 2011 and 2012, which decreased after that period. In 2015, volatility known a significant period thanks to slower economic growth in China due to lower oil prices and geopolitical instability.

At the beginning of the 2016 there is a high volatility this being sustained by turbulences that took places on the Asian stock exchanges and of course UK referendum also had an impact in increasing the volatility in June 2016.
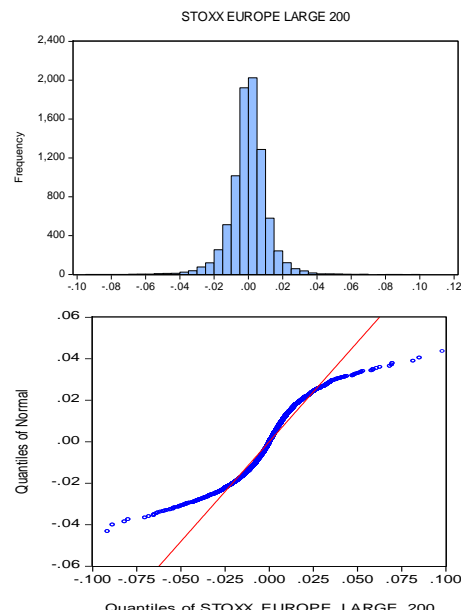
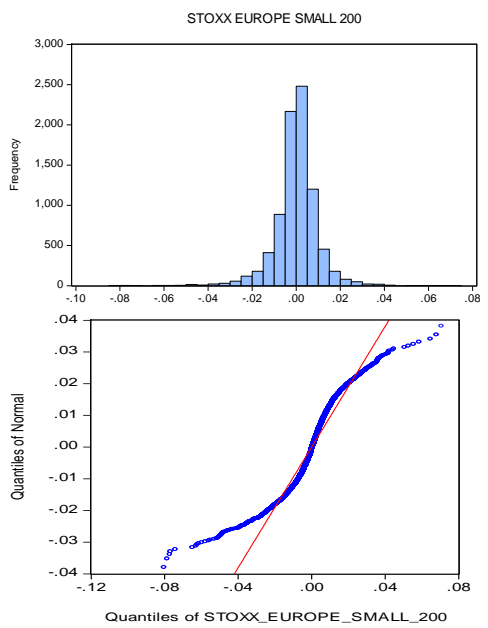

Figure 3. The Q-Q plot and the density graph

Source: Authors' work. 
What is the Causal Relationship between STOXX EUROPE 600 Sectors? But between Large Firms and Small Firms?

Table 7. Autocorrelation (AC), partial autocorrelation (PAC) and Q test with lag 20 for daily yields

\begin{tabular}{|c|r|r|r|r|r|}
\hline Variabiles & \multicolumn{1}{c|}{ Lag } & \multicolumn{1}{c|}{ AC } & \multicolumn{1}{c|}{ PAC } & Q-Stat & Prob \\
\hline STOXX EUROPE SMALL 200 & 20 & 0.015 & 0.015 & 146.86 & 0 \\
\hline STOXX EUROPE LARGE 200 & 20 & 0.024 & 0.021 & 77.453 & 0 \\
\hline \multicolumn{7}{|c}{ Source: Authors' work. }
\end{tabular}

Conditional volatility index STOXX LARGE 20

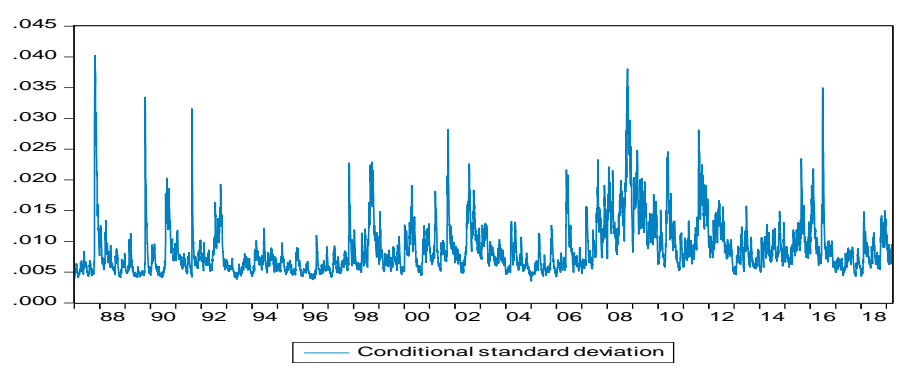

Figure 4. Volatility of STOXX LARGE 20 index

Source: Authors' work.

Conditional volatility index STOXX SMALL 200

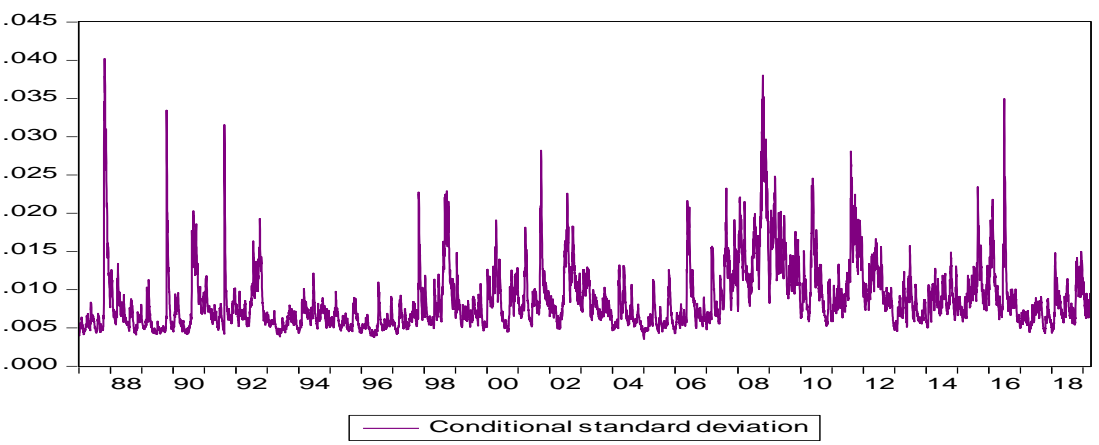

Figure 5. Volatility of STOXX SMALL 200

Source: Authors' work. 
Leonardo Badea, ValentinIonescu, Adina Alexandra Guzun

In the case of large and small companies, we observe a similar evolution with the sectors. But for these we managed to capture the evolution of volatility even before the 2000s.

The high volatility periods before the 2000s can be explained: in the $97-98$ period, the Asian crises occurred and it has a big impact on the market as Korea was at that moment one of the world's fastest growing economies. But because of weak financial supervision and the decrease of Japanese yen, Korea and other Asian countries have felt the effects of the crisis. The boom of the investments has stopped and companies from Asian countries encountered financial difficulties.

\section{Conclusions}

The main objective of this paper was to find outif there is a relationship between the main industries of the STOXX EURO 600 index. Also we wanted to provide evidence if there is a link between small and large firms. In order to achieve our objectives we used daily data between January 2001-March 2019, data sources is Datastream. We have selected a number of optimized STOXX indices representing various sectors of the economy (Banks, Health, Industrial Products and Services, Insurance, Personal and Household Products, Food \& Beverage, Petroleum and Gas, Chemicals, Telecom, Utilities, Retail, Auto and Parts, Mass Media, Basic Resources, Construction and Material, Real Estate, Travel and Leisure, Financial Services). As respects the relationships between small and large firms, we have selected two stock indices STOXX EUROPE SMALL 200 and STOXX EUROPE LARGE 200.

The main statistical tools used in this research are the VAR models, impulse-response functions, Granger causality test and GARCH models.

The empirical results pointed out the presence of a positive relationship between all the sectors selected and STOXX 600 index. The Granger causality test showed a unidirectional causal relationship from the insurance sector to STOXX 600 and a bidirectional causal relationship between automobiles \& parts, construction and material components, retail, telecommunications, utilities and STOXX600. Other interesting results that are worth mentioning regarding the causality between sectors: we identified two-way causal relations between: insurance and banks, insurance and financial services, health and financial services, oil and banks, insurance and automobiles \& parts, banks and cars, oil and financial services. The Granger causality test allows us to confirm the existence of a bidirectional causality between small companies and large companies.

The volatility analysis allowed us to see that it is affected by the economic or political events that took place during the analyzed period. The volatility had different evolutions over the analyzed period 2001-2019. The highest volatility can be noticed in 2008-2009 period, followed by a decreasing period, in 2010. A new episode of volatility was noticed in 2011 and 2012, which decreased in the next 
What is the Causal Relationship between STOXX EUROPE 600 Sectors? But between Large Firms and Small Firms?

period.In 2015, volatility known a significant period thanks to slower economic growth in China because of geopolitical instability and lower oil prices.

At the beginning of the 2016 there is a high volatility this being sustained by turbulences that took places on the Asian stock exchanges and of course UK referendum also had an impact in increasing the volatility in June 2016. In the case of large and small companies, we observe a similar evolution with the sectors.

We strongly believe that our results will be useful not only in theoretical and empirical academic work, but also to regulators and investors.

\section{REFERENCES}

[1] Conrad, J.,Gultekin, M., Kaul,G.(1991), Asymmetric Predictability of Conditional Variances; Review of Financial Studies, 4, pp.597-622;

[2] Francis, B.B., Hunter, D.M., Mougoué, M. (2003), Is There a Symmetric Nonlinear Causal Relationship between Large and Small Firms?,http://dx.doi.org/10.2139/ssrn.586544;

[3] Frimpong, J.M. and Oteng-Abayie, E.F. (2006), Modelling and Forecasting Volatility of Returns on the Ghana Stock Exchange Using GARCH Models; MPRA Paper No. 593, pp.1-21;

[4] Granger, C.W.J. (1969), Investigating Causal Relations by Econometric Models and Cross-spectral Methods; Econometrica, Vol. 37, No. 3,424-438;

[5] Hakkio, C.S.,Rush, M.(1991), Cointegration: How Short Is The Long Run, Journal of International and Money and Finance, pp.571-581;

[6] Ho, K.Y., Ernst, B.D., Zhang, Z.Y. (2011), Assessing the Dynamic Relationship between Small and Large Cap Stock Prices; 19th International Congress on Modelling and Simulation, Perth, Australia, pp.1554-1560;

[7] Hodgson, A., Masih, A., Masih, R. (1999), Dynamic Price Relationships between Small and Large Stocks; Accounting Research Journal, Vol. 12, No. 2, pp.151-162;

[8] Karmakar, M. (2006), Stock Market Volatility in the Long Run, 1961-2005; Economic and Political Weekly; Vol. 41, No. 18, pp. 1796-1802;

[9] Keim, D.(1983), Size-related Anomalies and Stock Return Seasonality: Further Empirical Evidence; Journal of Financial Economics, 12, pp.13-32;

[10] Lo, A.,MacKinlay,C. (1990), When are Contrarian Profits Due to Stock Market Overreaction?, Review of Financial Studies, 3,pp.175-205;

[11] Mishra, P.K., Das, K.B., Pradhan, B.B. (2009), Capital Market Volatility in India- An Econometric Analysis; The Empirical Economics Letters, 8(5), pp.450-477; 
Leonardo Badea, ValentinIonescu, Adina Alexandra Guzun

[12] Munteanu, A., Filip, A., Pece, A. (2014), Stock Market Globalization: The Case of Emerging European Countries and the US; Procedia Economics and Finance 15, pp. 91-9;

[13] Ng, S., Perron, P. (2001), Lag Length Selection and the Construction of Unit Root Tests with Good Size and Power; Econometrica; Wiley Online Library, pp.1-43;

[14] Pardo, A., Torro, H. (2003), Trading with Asymmetric Volatility Spillovers; Working paper, Universitat de Valencia, Valencia;

[15] Perez-Quiros, G., A. Timmerman (2000), Firm Size and Cyclical Variations in Stock Returns; Journal of Finance, 55, pp.1229-1262;

[16] Pesaran, H. H., Shin, Y. (1998), Generalized Impulse Response Analysis in Linear Multivariate Models;:Economics Letters,58(1), pp.17 -29. 